\title{
A pesquisa de História da América no Brasil durante as últimas décadas
}

José Luis Bendicho Beired*

Tem sido um lugar comum o argumento de que o Brasil está de costas para a América Latina. A explicação pode ser encontrada nas diferenças políticas e culturais, nas expectativas de futuro, assim como em um passado marcado por desconfianças e preconceitos em relação aos vizinhos hispânicos. Apesar disso, as forças que compeliram ao distanciamento foram contrabalanceadas por outras que concorreram para a aproximação e o conhecimento mútuo das sociedades americanas, cabendo à ciência e à cultura um importante papel nesse sentido. Fazemos esta breve consideração por acreditarmos que o interesse pelos estudos americanistas no Brasil, longe de ser uma decisão neutra, está fundada em inquietações de natureza política e cultural a respeito do lugar do nosso país na América e da construção de relações com as demais nações do continente.

No vigésimo aniversário da ANPHLAC, a proposta deste artigo é realizar um balanço da produção universitária brasileira no campo da História da América. Em 2004, a revista Diálogos trouxe a público uma entrevista com a Prof ${ }^{a}$. Maria Ligia Prado e três artigos relativos ao ensino, pesquisa e edições de História da América, os quais, no seu conjunto fornecem um mapa e pistas interessantes para a compreensão da evolução desse campo do conhecimento no Brasil (DIÁLOGOS, 2004). Em seguida, publicamos um catálogo de teses e dissertações de História da América elaboradas nas universidades paulistas e analisamos essa produção, tomando a USP, UNESP, UNICAMP e PUC-SP (BEIRED, 2004; 2005).

As dificuldades para levarmos a cabo um exame de dimensão nacional são maiores em vista dos inúmeros departamentos de história e de cursos de pós-graduação que tem promovido tais estudos. Como realizar a uma análise satisfatória das características de uma produção desenvolvida em regiões e instituições as mais diversas? Quais as questões e temáticas que pautaram as pesquisas? É produtivo estabelecer uma comparação entre as instituições? É possível ir além de uma mera fotografia, de uma imagem estática, e explicar a dinâmica que presidiu a produção ao

\footnotetext{
* Professor do Departamento de História da Universidade Estadual Paulista (UNESP/Assis). E-mail: jbbeired@assis.unesp.br
} 
longo do tempo? Trata-se, pois de indagar a respeito da constituição de um campo do conhecimento que como tantos outros são relativamente recentes no Brasil e sobre o qual ainda carecemos de reflexões sistemáticas. Em vista disso, a opção tomada para a elaboração deste artigo pode não ser a ideal, mas apresenta-se por ora como a mais viável. Baseados no levantamento das teses e dissertações defendidas nos programas de pós-graduação buscaremos estabelecer um quadro amplo que permita visualizar elementos relevantes para a compreensão do desenvolvimento da pesquisa de América. ${ }^{1}$

As universidades incidiram sobre os estudos americanistas por meio da criação dos primeiros cursos de História nos anos 1930. A criação da USP foi um marco no desenvolvimento do ensino superior ao integrar a docência à pesquisa e estabelecer no Brasil padrões de trabalho científico em sintonia com o ambiente universitário internacional. A participação da missão francesa nos primeiros anos de formação da Faculdade de Filosofia e, em especial, do curso de História e Geografia, foi decisiva na trajetória de tais especialidades nas décadas seguintes. ${ }^{2}$ As primeiras teses de doutorado de História da América da USP foram orientadas pelo Prof. Jean Gagé: O comércio no Rio da Prata. 1580 - 1640, de Alice Canabrava (1942), A política colonial de Espanha através das encomiendas, de Astrogildo Rodrigues de Mello (1942) e A penetração comercial da Inglaterra na América Espanhola. 1713 - 1783, de Olga Pantaleão (1944). Como característica geral, tais trabalhos versavam sobre história econômica colonial, evidenciando objetos e abordagens filiadas ao programa dos Annales.

O impulso dado por esses estudos pioneiros não encontrou continuidade nos anos imediatamente subseqüentes e as pesquisas tiveram que aguardar mais de duas décadas para a sua retomada no âmbito do Departamento de História da USP. Uma vez reiniciadas, entre o final dos anos 60 e o final dos 70, dois terços das teses e dissertações de América versaram sobre História Econômica. A força dessa vertente nos estudos americanistas refletia uma tendência da produção histórica brasileira de então, voltada à busca de explicações estruturais do passado, nas quais a esfera da economia desempenhava o papel determinante em relação aos demais domínios da realidade. No caso da História da América da USP foram realizadas várias pesquisas sobre produção,

\footnotetext{
1 Os dados foram levantados por meio da consulta bibliográfica, dos portais dos programas, das bibliotecas universitárias e da Plataforma Lattes, buscando abranger o período coberto entre a realização das primeiras defesas e o ano de 2012. O trabalho de coleta contou com a fundamental colaboração de Paula da Silva Ramos e Renato Santejo Saiani, pós-graduandos da UNESP/Assis.

${ }^{2}$ Sobre a criação dos primeiros cursos de História ver CAPELATO, 1995;
} 
comércio, administração e ocupação territorial, a exemplo de $A$ instituição do comércio marítimo das Índias: a carreira de Buenos Aires (1767 - 1779), de Manoel Lelo Bellotto; A presença portuguesa no Peru em fins do século XVI e princípios do XVII, de Yara Monteiro, e Comércio exterior e política interamericana: Chile no conflito hispano-peruano de 1864-1865, de Héctor Bruit.

Nos anos 1970, foram estabelecidos programas de pós-graduação em História em diversos lugares do país que permitiram a formação de novos núcleos de pesquisa e de historiadores para um mercado de trabalho universitário em expansão: PUC-RS (1970), UFF (1971), UFPR e PUC-SP (1972), UNB e UNICAMP (1976), UNESP/Assis (1978) e UNESP/Franca (1979). As suas primeiras dissertações de América começaram a ser defendidas em 1979 e as teses alguns anos depois com a implantação dos cursos de doutorado.

A UFF se particulariza pela precocidade das primeiras defesas de mestrado e o considerável número de orientadores e dissertações dedicadas aos estudos americanos. Pode-se dizer que estes conheceram duas fases. A primeira, situada entre 1971-1981, teve como resultado a confecção de 30 dissertações; e a segunda, de 1990 em diante, cerca de 44 trabalhos de doutorado e mestrado. Foi bastante expressivo o rol de orientadores da primeira fase - Pedro Freire Ribeiro, Artur Cézar Ferreira Reis, Steven Topik, Francis William Orde Morton, Roy Arthur Glasgow. As dissertações desse período priorizaram a história política seguida pela história econômica, em vários casos na perspectiva das relações internacionais. Caracterizadas por títulos gerais e temas amplos, as monografias denotam o esforço pioneiro no sentido de uma primeira aproximação aos temas abordados. Também chama a atenção o domínio absoluto do interesse pelo período contemporâneo, com a ausência de trabalhos sobre o período colonial, assim como o elevado número de orientações, em contraste com a preferência pelos temas coloniais na USP e o declínio das defesas de América nessa instituição, em fins dos anos 1970. Em convergência com os estudos da historiografia latino-americana de então, parte das pesquisas esteve focada na compreensão do processo político do século XIX e a consolidação do Estado Nacional mediante o estudo monográfico de experiências governamentais da América do Sul, assim como das idéias políticas de líderes tais como Simon Bolívar e Domingo F. Sarmiento. As abordagens econômicas também estiveram em pauta, com pesquisas sobre o café na Colômbia, o petróleo na 
Venezuela, a economia argentina e os programas de integração no âmbito da ALALC. Outros trabalhos se debruçaram sobre questões internacionais elegendo como temas o Congresso Panamá e as relações do Brasil com a Bolívia em torno da questão do Acre. Os temas sociais e culturais foram exceção, a exemplo dos estudos sobre o índio na literatura peruana, a questão indígena na Argentina e as relações raciais em Cuba. Desde logo, coloca-se um problema a merecer uma análise especifica em relação à UFF: a descontinuidade do trabalho de orientação na área de América, uma vez que as defesas cessaram em 1981 e somente foram reiniciadas em 1995, sob a orientação de um novo corpo de professores.

\section{Os anos 1980: um novo impulso}

A conjuntura histórica brasileira da década, pautada pelo combate ao regime militar, por mudanças sociais e pela identificação com as causas democráticas latinoamericanas, conformou um ambiente estimulante para as pesquisas e se refletiu no incremento do mercado editorial de literatura, atualidades e ciências sociais sobre o continente. No campo historiográfico assistiu-se ao declínio da história econômica desde o final da década anterior, fenômeno já estudado em relação à produção da USP, UFF e UFRJ e que também atingiu os demais cursos de História (FRAGOSO; FLORENTINO, 1997, p. 28; LAPA, 1976, p. 89). A crise dessa corrente foi acompanhada da renovação da historiografia nacional, tendo como referência a terceira geração dos Annales e os trabalhos dos historiadores marxistas britânicos.

O crescente interesse do público pelas questões americanas também contribuiu para a emergência de outro ciclo de produção de pesquisas de América caracterizado pela formação novos núcleos de investigação em vários estados e pela diversificação temática segundo os interesses regionais. Por exemplo, nos cursos do Rio Grande do Sul as questões envolvendo a fronteira e o espaço platino tornaram-se centrais; na UNB as relações internacionais; na UNICAMP, a história do trabalho; na UNESP/Assis foi criada uma linha de pesquisa sobre a história do capitalismo na América Latina. Como marca geral, desenvolveu-se a crítica aos antigos dualismos, aos modelos generalizantes das ciências sociais, ao eurocentrismo e às explicações simplificadoras da história latino-americana que a tomavam como mera caixa de ressonância de fenômenos externos. 
Na USP, o conjunto de pesquisas dos anos 1960/1970 não se traduziu na conformação de um campo estável e consolidado junto ao Departamento de História e, ao lado do esgotamento dos estudos econômicos, assistiu-se ao declínio abrupto de defesas nos anos 1980. Em meados da década, o trabalho de orientação foi retomado, cabendo à Prof ${ }^{a}$ Maria Ligia Prado um papel fundamental na reestruturação da área. Docente da disciplina História da América Independente desde 1975, após o seu doutoramento, em 1982, desenvolveu inúmeras atividades que revigoraram a área. Realizou pesquisas inovadoras, ministrou inúmeras disciplinas de pós-graduação e orientou dezenas de teses e dissertações focadas nos estudos latino-americanos, formando historiadores que tem promovido os estudos americanistas em diversas universidades brasileiras. Dentre outras atividades, vale lembrar a coordenação daquilo que ficou conhecido como Grupo de Estudos de América Latina, reunindo alunos de diversos níveis, e a fundação da Associação de Estudos Latino-Americanos (AELA) ${ }^{3}$, entidade que desenvolveu inúmeras iniciativas acadêmicas - eventos, cursos, seminários de estudo, debates de pesquisa, publicações - e inspirou a futura criação da ANPHLAC. Naquele contexto vários alunos egressos da graduação iniciaram as pesquisas sob a orientação da professora Ligia Prado, com os seguintes trabalhos de mestrado: "Uma Consciência em Marcha”: o Partido Laborista e as origens do peronismo (1930-1946), de José Luis B. Beired; A estratégia democrática ao socialismo e o governo Allende: uma contribuição ao estudo da esquerda chilena, de Alberto Aggio; e Personagens em busca de um autor: participação dos militares na política argentina (1930-1976), de Júlio Pimentel Pinto Filho. A professora também deu início aos doutoramentos, com os trabalhos de Zilda G. Iokoi, Igreja e camponeses, Teologia da Libertação e movimentos sociais no campo: Brasil/Peru - 1964-1986; Heloísa Reichel, Contribuição para o estudo da formação capitalista na América Latina: o caso da campanha de Buenos Aires (1830-1840); e Philomena Gebran, A historiografia sobre as sociedades andinas: Peru (1920-1980). Os primeiros trabalhos eram indicativos do interesse existente em temas políticos que remetiam diretamente aos problemas do presente e nos últimos dominavam as preocupações em torno das questões econômicas e sociais, à luz de novas perspectivas teóricas em relação às décadas anteriores. Ademais, foram realizados por meio da investigação de fontes e de bibliografia coletadas no exterior e inauguraram

\footnotetext{
${ }^{3}$ Desenvolveu atividades entre 1982 e 1985. 
uma nova etapa de trabalho na pós-graduação que se mostrou dotada de continuidade no futuro.

As dissertações iniciais da PUC-RS e da UNB já esboçavam os seus respectivos campos de interesse. Na primeira, A organização política das missões da Província Jesuítica do Paraguai, de Arno Kern, e na segunda, Episódios da política externa do Brasil no Prata, de Maria E. Ribeiro. ${ }^{4}$ Dentre os trabalhos posteriores, defendidos na década de 1980, da UNB são representativos: As relações Brasil - Estados Unidos e o capital norte-americano (1955-1965), de autoria de Fabio Ferreira Batista; As relações entre o império do Brasil e a República do Paraguai (1822-1889), de Francisco F. M. Doratioto e A política do império brasileiro para as repúblicas do Pacifico, de Luis Claudio Villafañe dos Santos. Por sua vez, dos mestrados concluídos na PUC-RS, dois versavam sobre a história indígena no período colonial - a exemplo de Os movimentos guarani de resistência à colonização da Bacia Platina (1537-1660), de Maria Cristina dos Santos - e outros tratavam problemas internacionais: Aviação Comercial na América do Sul (1920-1941), de Cláudia Fay; e Brasil e Argentina frente à questão do Chaco: a supremacia da América do Sul em jogo, de Helder V. Gordim Silveira.

Ainda que nos anos oitenta tenhamos assistido a um modesto volume de trabalhos defendidos - nos quais os doutorados eram exceção - consideramos que tiveram um papel decisivo na organização da área, cujos desdobramentos se materializaram no incremento das investigações realizadas anos seguintes. Além do estímulo à orientação de pesquisas de América nos cursos de graduação, foi muito importante a oferta de disciplinas especificas na pós-graduação de modo a aprimorar a formação especializada de alunos que posteriormente viriam a ocupar posições de docência e pesquisa no sistema universitário brasileiro.

\section{Os anos 1990: em direção à consolidação}

Alguns episódios do período foram importantes para a trajetória da área. Em 1990, foi realizado o Congresso Internacional da ADHILAC e dois anos depois o Congresso Internacional América 92: Raízes e Trajetórias, na Universidade de São Paulo. Ambos permitiram a reunião de inúmeros pesquisadores de americanistas do

\footnotetext{
4 As duas dissertações foram as únicas defendidas na década de 1970, sendo que as seguintes foram apresentadas a partir de 1981 (UNB) e 1983 (PUC-RS).
} 
Brasil e do exterior e evidenciaram de forma clara o crescimento do interesse na pesquisa de América. Para dar corpo à aspiração por uma entidade científica da área, em janeiro de 1992 e de 1993 foram realizadas reuniões que resultaram na fundação da ANPHLAC. ${ }^{5}$

Um aspecto marcante foi o rápido crescimento quantitativo das pesquisas. As defesas de doutorado da USP aumentaram em relação à década anterior e as primeiras começaram a ser realizadas em outras instituições - UnB, UFF, PUC-RS e UNESP. Na USP, a renovação da área América, com o ingresso de Maria Helena Capelato, Janice Theodoro da Silva e Werner Altman, entre a segunda metade dos anos 80 início dos 90 favoreceu a ampliação e diversificação das pesquisas orientadas. Os objetos, fontes e abordagens multiplicaram-se, com o predomínio da história cultural, seguida pela história política e econômica. ${ }^{6}$ A dimensão cultural, freqüentemente articulada à política, presidiu uma série de estudos a respeito de intelectuais, imprensa, cinema, música e religião. A narrativa literária foi tratada em Borges, uma memória do mundo: ficção, memória, história, de Júlio Pimentel Pinto Filho; o papel das revistas brasileiras na difusão de visões sobre os Estados Unidos e a América Latina foi examinado em pesquisas como Ao sul do Rio grande. Imaginando a América Latina em Seleções (1942-1970), de Mary Anne Junqueira, e Um continente em foco: a imagem fotográfica da América Latina nas revistas semanais brasileiras (1954 - 1964), de Rafael Baitz; a revolução cubana em Cultura e política em Cuba: os debates em Lunes de la Revolución, de Silvia Miskulin; a música em Tropicalismo (1967 - 1969) e Grupo de Experimentación Sonora (1969 - 1972): engajamento e experimentalismo na canção popular, no Brasil e em Cuba, de Mariana Villaça; a comparação também foi estabelecida entre intelectuais do Brasil, México e Argentina, a exemplo de Messianismos culturais: Monteiro Lobato e José Vasconcelos e seus projetos para a nação, de Regina Crespo. O período colonial foi objeto de atenção em trabalhos a respeito da obras dos cronistas e da religião tais como Formas de representações religiosas no Brasil e no México do século XVI, de Leandro Karnal; e Os mitos e deuses

\footnotetext{
${ }^{5}$ Em 25 de janeiro de 1992 formou-se em São Paulo a Comissão Nacional de Pesquisadores de História Latino-Americana e Caribenha, a qual se reuniu na UFOP, campus de Mariana, em 12 e 13 do ano seguinte, com a presença de representantes de várias partes do país, para fundar a Associação Nacional de Pesquisadores de História Latino-Americana e Caribenha.

${ }^{6}$ Vale lembrar a atuação do Prof. Osvaldo Coggiola, da área de História Contemporânea, que orientou trabalhos junto ao Programa de História Econômica.
} 
mesoamericanos através da crônica espanhola na época a conquista, de Eduardo Natalino dos Santos.

O processo político, a ação dos atores e as ideologias balizaram outro grupo de trabalhos da USP, a exemplo das teses: A Frente Popular no Chile: história e historiografia, de Alberto Aggio; Autoritarismo e nacionalismo: o campo intelectual da nova direita no Brasil e na Argentina (1914-1945), de José Luis B. Beired; Tecendo os fios da nação. Soberania e identidade nacional no processo de construção do Estado argentino, de Antonio Carlos Amador Gil; e das dissertações A Questão Nacional em Porto Rico: o Partido Nacionalista (1922-1954), de Kátia Gerab Baggio, e Projetos políticos de modernização e reforma no Peru: 1950 - 1975, de Gabriela Pellegrino Soares. As relações do Brasil com o continente foram analisadas em vários estudos, destacando-se os doutorados: A "Outra América": a América Latina na visão dos intelectuais brasileiros das duas primeiras décadas republicanas, de Kátia Gerab Baggio; Em nome da América: os Corpos da Paz no Brasil (1961-1981), de Cecília Azevedo; A hegemonia dos Estados Unidos e a trajetória do desenvolvimento latinoamericano: aspectos políticos e econômicos (1945-1990), de Fernando Ayerbe; e a dissertação Estado e nação: a crise dos impérios ibéricos no Prata (1808 - 1828), de João Paulo Garrido Pimenta. Em menor número foram elaborados trabalhos de história econômica e social tais como Os setores populares frente ao desenvolvimento do capitalismo na província de Córdoba (1861 - 1914), de Luiz Felipe V. Moreira; $O$ campesinato e a Revolução Cubana, de José Rodrigues Mao Júnior; e Terra e capitalismo na América Latina: reformas na legislação agrária de Nova Granada (1848 - 1853), de Cristiane Checchia.

Paralelamente, as pesquisas realizadas pelos orientadores se materializaram em teses de livre-docência que foram publicadas e se tornaram referência em vista das inovações temáticas, teóricas e metodológicas. Dois trabalhos foram significativos: Multidões em cena: propaganda política no varguismo e peronismo, de Maria Helena Capelato, e A América Latina no século XIX: tramas, telas e textos, de Maria Ligia Prado. Com um original recorte comparativo, o primeiro discutiu as estratégias da política de massas e a construção dos imaginários sociais no Brasil e na Argentina. E o segundo discutiu os dilemas políticos e as representações culturais por meio de ensaios que se debruçaram sobre as obras clássicas, as pinturas e as desventuras de homens e 
mulheres que lutaram pelos ideais revolucionários. Ainda que as duas pesquisas fossem bastante diversas, possuíam um núcleo de preocupações comuns sobre as relações entre política e cultura, comparação e estudo de fontes. Era a expressão da trajetória paralela de duas historiadoras cuja colaboração acadêmica veio a propiciar um notável impulso aos estudos brasileiros de América contemporânea.

Em relação à UnB, a inserção do curso de história na capital do país conferiu um lugar de proa às relações internacionais. As inúmeras instâncias federais que debatem e deliberam sobre as questões externas, a concentração de embaixadas e de sucursais de órgãos da grande imprensa são responsáveis pela manutenção de ambiente carente e ao mesmo tempo estimulante de análises fundamentadas dos assuntos internacionais. Criado em 1976, teve como orientadores principais Amado Cervo, Jaime de Almeida, Geralda Dias Aparecida e José Flávio S. Saraiva. A maior parcela dos trabalhos da UnB dos anos 90 trata das relações políticas, econômicas e diplomáticas do Brasil, predominando os estudos sobre as relações com os países sul-americanos, em especial do Prata. A política exterior do Brasil para a Argentina foi tomada sob inúmeros aspectos que vão das ações do Império ao conflito Malvinas/Falklands, passando pela atuação do Barão do Rio Branco e pelas experiências de integração econômica e por contenciosos como o de Itaipu. Pesquisas se dedicaram às relações com o Paraguai, Bolívia e Cuba tanto na dimensão política quanto econômica e o pensamento americanista foi discutido à luz das idéias de José Martí e Domingo Faustino Sarmiento.

O programa de Pós-Graduação em História da PUC-RS teve a primeira dissertação da área de América defendida em 1978. O pronunciado interesse americanista reflete-se na área de concentração do programa, denominada História das sociedades ibéricas e americanas, com um corpo docente integrado por Arno Kern, Braz Augusto A. Brancato, Earle M. Moreira. Sandra Maria Brancato, Maria Cristina dos Santos, Dorivaldo W. Poletto e Helder G. da Silveira. Os trabalhos da PUC-RS se distribuem entre relações internacionais, história política e econômica, tanto do período colonial quanto dos séculos XIX e XX. O primeiro doutoramento, defendido em 1995 , intitulou-se Guerra irregular en espacios andinos y en la pampa gaucha: el caso de la Banda Oriental del Uruguay (1808-1820), de Eduardo Perez Ochoa. Em relação à história colonial os principais objetos estudados versaram sobre a organização das fronteiras e do espaço urbano, as missões jesuíticas tanto na dimensão política quanto 
cultural, a história indígena em suas novas abordagens, as relações dos vice-reinados Prata e Peru com a América Portuguesa, as reformas bourbônicas e as guerras de independência. Os temas políticos mostram-se dominantes nas pesquisas do período independente, tendo o Uruguai, a Argentina e o Paraguai como focos principais. O Uruguai foi estudado tanto em relação ao processo de transformações no século XIX quanto na resistência política ao autoritarismo político no XX. Por sua vez, os países acima também foram examinados na perspectiva das relações internacionais, em trabalhos sobre as relações entre a Província Cisplatina e o Império, as vinculações entre o Rio Grande do Sul e o Uruguai, O Pacto ABC, as relações Brasil-Argentina e a formação de uma identidade regional platina. No campo da economia receberam atenção os projetos da CEPAL, as transformações econômicas regionais e as ações de integração.

Por sua vez, na UFF assistiu-se à retomada da orientação na área de América nos anos 90, juntamente com a organização de um novo corpo de orientadores - Marco Antonio Pamplona, Ronaldo Vainfas e Cecília Azevedo. Os temas contemporâneos em perspectiva cultural ocuparam considerável atenção, a exemplo da teses Mitografia da experiência argentina: sociogênese do tango em Buenos Aires, de Marcelo Carlos Gantos; A dança de Clio e Calíope: uma leitura interdisciplinar dos protestos dos jovens norte-americanos nos anos 60, de Eliane Borges Berutti; e da dissertação A noite dos Kygua Vera. A mulher e a reconstrução da identidade nacional paraguaia (18691904), de Alberto Moby R. da Silva, além de outros relativos à cultura de protesto nos EUA, à historiografia, povoamento e manifestações religiosas indígenas.

Na UNESP, a pós-graduação em História conta com dois programas, dos Campus de Franca e de Assis, cujas primeiras dissertações de mestrado foram A idéia de América no pensamento de Buffon, de Célia Maria David (1988) e A integração latino-americana: a experiência argentina e brasileira na ALALC, de Patrícia Malheiros (1990). Até o final doa anos 90, foram concluídos outros onze trabalhos nos dois cursos, em torno de temas acerca da história econômica, política e das idéias, divididos entre o período colonial e independente, tendo como primeiro doutorado a monografia Cisplatina: estado federado ao Brasil, de Enrique Peregalli.

Paralelamente, outros cursos de pós-graduação iniciaram as suas atividades e passaram a desenvolver orientações de História da América. Na UNISINOS foram 
apresentadas as primeiras dissertações, a exemplo de A instituição municipal na América de colonização ibérica, de Alcindo Arnhold; Payaguá: os senhores do Rio Paraguai, de Magna Magalhães; Concepções de república na região platina á época da Revolução Farroupilha, de Eduardo Scheidt; As ferrovias no Rio grande do Sul e no Uruguai (1870-1920): um estudo comparativo, de Antonio Ransolin. Era notório o esforço no sentido da compreensão do sul do Brasil colonial nas suas diversas articulações com o restante da região platina. Mostraram-se preponderantes os trabalhos sobre os povos autóctones, tanto do ponto de vista da organização social e política quanto do imaginário religioso, ao lado daqueles dedicados ao papel dos missionários jesuítas no Prata, ainda que alguns se debruçassem sobre o período contemporâneo no estudo de questões políticas e econômicas. Na UFRGS, a ênfase dos mestrados incidiu sobre assuntos políticos e econômicos dos séculos XIX e XX, em especial a formação da mão de obra, economia, política e diplomacia: Caudilhos e Montoneros de La Rioja: sociedade e discurso (1862-1867), de César Augusto Barcellos Guazzelli; A Revolução Mexicana (1910-1940): um caso de hegemonia burguesa na América Latina, de Cláudia Wasserman; A elite diplomática brasileira e as visões sobre a Argentina durante o Estado Novo, de Eduardo Svartman; e O processo de organização de uma ordem capitalista urbana numa cidade do interior argentino: Córdoba - 1895-1906, de Luiz Felipe Viel Moreira.

\section{O século XXI: um campo consolidado}

O lugar conquistado pela pesquisa em História da América na primeira década deste século é notável. Podemos observar o aprofundamento das tendências dos anos noventa: credenciamento de novos orientadores, aumento do número de teses e dissertações defendidas, crescimento quantitativo dos trabalhos de história cultural, forte interesse pela nova história política; atualização em relação às correntes historiográficas internacionais e diversificação temática, teórica e metodológica.

A crítica aos modelos generalizantes implicou a valorização da pesquisa de fontes e da singularidade das experiências históricas. $\mathrm{O}$ questionamento dos determinismos pôs em evidência novas dimensões da realidade relacionadas à subjetividade dos agentes históricos e a multiplicidade dos imaginários sociais coletivos em função das divisões étnicas, políticas e regionais. Também se verificou o aumento 
de trabalhos sobre relações internacionais, o que pode ser explicado pela relevância que essa dimensão da realidade tem conquistado nos dias correntes e na emergência de uma nova sensibilidade entre os historiadores em relação ao papel dos fenômenos internacionais. Por sua vez, se multiplicaram os trabalhos sobre novos objetos e apoiados em fontes pouco utilizadas anteriormente, como atestam os estudos sobre imprensa, propaganda política, viagens, leitura, fotografia, literatura, livros didáticos, gênero, cinema, rádio, música, cidades, religião e antigas culturas indígenas, entre outros. Finalmente, a história comparada, com pouca tradição na historiografia brasileira, foi estimulada pelos estudos de América e proporcionou resultados inovadores.

Nas universidades paulistas o aumento de pesquisas respondeu tanto à demanda interna fomentada pelos seus respectivos alunos de graduação quanto pela procura de uma clientela proveniente de outras regiões do país. No Programa de História Social da USP novos professores passaram a atuar como orientadores: Júlio Pimentel Pinto Filho, Mary Anne Junqueira, Gabriela Pellegrino Soares, Horácio Gutierrez e Eduardo Natalino dos Santos. A cultura e a política constituíram as duas principais vertentes de desenvolvimento das pesquisas na investigação de objetos muito diversificados. No campo da história cultural foram desenvolvidos: Peregrinas de outrora: viajantes latino-americanas no século XIX, de Stella Maris Franco Vilardaga; As representações temporais na obra de Juan Rulfo, de Paulo Ferraz de Camargo; Bartolomé de las Casas: a narrativa trágica, o amor cristão e memória Americana, de José Alves Freitas Neto; A Semear Horizontes: leituras literárias na formação da infância na Argentina e no Brasil (1915-1954), de Gabriela Pellegrino Soares. Com uma abordagem política dois trataram do pan-americanismo: A infância como portadora do futuro da América Latina (1916-1948), de Eduardo S. N. Nunes, e O Brasil e os demais países latinoamericanos nas Conferências Pan-Americanas, de Teresa Spyer Dulci; outros discutiram a esquerda em A comuna de La Paz: história da Assembléia Popular de 1971 na Bolívia, de Everaldo de O. Andrade; e Teologia da Libertação na Nicarágua Sandinista, de Fábio Claus Morlina.

Porém, uma parcela muito considerável foi desenvolvida na interface entre nova história política e a história cultural. No âmbito da produção áudio-visual vale citar $A$ política cultural do governo cubano e o ICAIC - Instituto Cubano de Arte e Indústria 
Cinematográfica (1971-1986), de Mariana Villaça; O império das imagens de Hitler: o projeto de expansão internacional do modelo de cinema da Alemanha nazi-fascista na Europa e na América Latina (1933-1955), de Wagner Pereira; A fotografia a serviço de Clio: uma interpretação da história visual da Revolução Mexicana, de Carlos Alberto S. Barbosa; Brigadas muralistas e cartazes de propaganda da experiência chilena (1970-1973), de Carine Dalmás. O confronto entre populações autóctones e a expansão da civilização ocidental foi examinada em $O$ mundo interligado: poder, guerra $e$ território nas lutas na Argentina e na Nova Zelândia, de Gabriel Passetti; a história intelectual pautou pesquisas como José Vasconcelos: as memórias de um profeta rejeitado, de Romilda Costa Motta, e Os intelectuais cubanos e a política cultural da Revolução (1961-1975), de Silvia Miskulin. Também é significativo o interesse pelos livros didáticos enquanto fonte e objeto de estudo, a exemplo de Luzes e sombras na construção da nação Argentina: os manuais de história nacional (1868-1912), de Stella Maris F. Vilardaga, e Concepções de história e de ensino em manuais para o ensino médio brasileiros, argentinos e mexicanos, de Vitória Rodrigues e Silva.

Em história econômica foram dirigidos trabalhos voltados para o período recente, tais como Che Guevara e o debate econômico em Cuba (1961-1964), de Luiz Bernardo Pericás; e Planos de estabilização econômica na América Latina na década de 1990, de José Menezes Gomes. Por sua vez, a história das civilizações précolombianas, assim como do seu contato com os espanhóis, possui escassos estudos em vista de diversas dificuldades técnicas, mas o seu desenvolvimento pode ser atestado pelo doutorado de Eduardo Natalino dos Santos, Calendário, cosmografia e cosmogonia nos códices e textos nahuas do século XVI.

Na UNESP/Franca a maior parte dos trabalhos foi defendida a partir de fins dos anos 1990, como resultado da atuação de uma nova geração de professores, vários especializados nos temas americanos: Alberto Aggio, Tânia da Costa Garcia e Héctor Luis Saint-Pierre. A história política foi o campo da maior parte das pesquisas, seguida pelos estudos de relações internacionais e de história da cultura. Um volume significativo de trabalhos girou em torno do pensamento latino-americano, nos quais foram estudados comparativamente Nina Rodrigues e Fernando Ortiz, Alberto Torres e Andrés Molina Enriquez, Darcy Ribeiro e Luis Alberto Sánchez, enquanto ideário socialista foi analisado em Utopia andina e socialismo na historiográfica de Alberto 
Flores Galindo (1970-1990), de Marcos S. Pinheiro. Por sua vez a questão do liberalismo assumiu papel central no exame da modernidade em Octávio Paz e das idéias políticas de Estebán Echeverría, José Martí, José Enrique Rodó, ao passo que Simon Bolívar foi examinado mediante um original estudo a respeito da memória inscrita no seu epistolário. Outros buscaram a compreensão da cultura política imanente a certas experiências: o batllismo, o foquismo, o socialismo chileno, o reformismo venezuelano e mesmo o anti-peronismo dos intelectuais argentinos. As relações internacionais ocuparam outro elenco de trabalhos, notadamente a respeito do papel dos militares e da diplomacia, com ênfase nos Estados Unidos e no Cone Sul durante as últimas décadas, a exemplo de Diplomacia e defesa na gestão Fernando Henrique Cardoso (1995-2002). História e conjuntura na análise das relações com a Argentina, de Érica Cristina Winand. Ainda que em pequeno número, os estudos culturais indicam uma tendência de desenvolvimento, materializada em dissertações a respeito da produção musical, como Nacionalismo e música erudita de vanguarda no Brasil e Argentina (1930-1960), de Mario André Ornaghi. .

No programa da UNESP/Assis, a orientação dos últimos anos foi levada a cabo por Carlos Alberto S. Barbosa, José Luis B. Beired e Clodoaldo Bueno. As questões internacionais constituíram uma vertente dos trabalhos realizados, com estudos sobre o século XIX, relativos às relações do Brasil com a Banda Oriental do Uruguai, do comércio e navegação nos rios platinos e a Guerra do Pacifico; e sobre o século XX, em torno das relações entre os países do Cone Sul, em Diplomacia integração $e$ desenvolvimento: Brasil e Argentina (1950-1962), de Iuri Cavlak, e Relações militares no Cone Sul: da rivalidade à cooperação na área de segurança (1964-2007), de Sérgio Cruz Aguilar. No campo dos estudos políticos, foram trabalhadas as relações de poder oligárquico na Colômbia, as posições da imprensa e do movimento operário em relação ao sandinismo e à Revolução Mexicana - Operários e camponeses. A repercussão da Revolução Mexicana na imprensa operaria brasileira (1910-1920), de Fábio da S. Souza - a organização política dos indígenas de Chiapas, as relações da extremaesquerda do Brasil com a Revolução Cubana, ao lado da história política uruguaia, com a tese A unidade política das esquerdas no Uruguai: das primeiras experiências à Frente Ampla (1958-1973), de André Lopes Ferreira. Uma tendência significativa tem sido o crescente número de trabalhos relativos à história cultural, a exemplo do exame 
dos escritores exilados cubanos, do ensaísmo de Octávio Paz, das representações do cinema norte-americano sobre a Revolução Mexicana, da questão racial e imigratória na Argentina e da identidade da mulher espanhola e americana no século XIX. Os estudos coloniais se fizeram presentes na análise dos cronistas, viajantes e do imaginário religioso, a exemplo do mito de Santiago.

Caracterizada no seu início pela ênfase na história do trabalho no Brasil, a pósgraduação da UNICAMP abriu-se a outros campos de investigação tais como cultura, memória e cidades, assim como à contratação de especialistas da área de América tais como os Profs. Leandro Karnal e José Alves de Freitas Neto. A história do trabalho tem se beneficiado da constante atualização teórica e se aberto a novas abordagens, sob a orientação de Cláudio Batalha e Michael Hall, em estudos sobre os operários na Argentina, a exemplo de No país da Cocanha: aspectos do modo de vida dos trabalhadores de Buenos Aires (1880-1920), de Norberto Ferreras. Desde o início deste século vem se destacando as pesquisas relativas à história colonial com ênfase nas representações e práticas cultural-religiosas de indígenas e eclesiásticos. Diversos estudos dedicaram-se aos relatos de cronistas espanhóis - A crônica jesuítica do século XVIII, de Luiz Estevam de Oliveira Fernandes; Da Idolatria indígena à conversão cristã no México do século XVI: uma análise da obra de frei Toríbio Motolinía, de Anderson Roberti dos Reis - assim como à investigação dos códices meso-americanos. A história cultural se fez presente nos estudos relativos aos intelectuais, à literatura e ao cinema: ¿Alpargatas sí, libros no? Produção cultural e legitimidade política durante o governo de Perón (1946-1955), de Paulo Renato da Silva, e De Macondo a McOndo: os limites do real maravilhoso como discurso de representação da América Latina (19531966), de Felipe de Paula G. Vieira. Com uma abordagem historiográfica foi investigada a produção da American Historical Review, e representações dos indígenas andinos e dos camponeses mexicanos. Minoritários, os temas políticos informaram nas dissertações a respeito da representação de José Artigas na celebração do centenário da sua morte, do discurso político de Lázaro Cárdenas e dos piqueteros argentinos.

As pesquisas da PUC-SP estiveram concentradas no período colonial, sob a orientação do Prof. Fernando Torres Londoño, dedicadas à ação dos missionários, especialmente na região amazônica e no México, a exemplo de Sahagun e as festas agrícolas mexica: em busca de um sentido, Karen Arriagada Valdivia, e Embates pela 
memória: narrativas de descoberta nos escritos coloniais da Amazônia Ibérica, de Juliana Pedro. Outros trabalhos foram dedicados à política - Peronismo em Primera Plana: uma história do peronismo numa revista argentina dos anos sessenta, de Marisa Montrucchio, ao lado discurso aprista e do cotidiano da Guerra do Paraguai - assim como à sua articulação com a literatura, em A morte e a vida da Revolução Mexicana: "Los de Abajo" de Mariano Azuela, desenvolvido por Carlos Alberto Sampaio Barbosa.

$\mathrm{Na} \mathrm{UnB}$, ainda que as relações internacionais continuem pautando a maioria das pesquisas, outras abordagens ganharam espaço, vinculadas à história cultural e social, do imaginário e do cotidiano. Aos orientadores dos anos 90, outros se somaram: Francisco F. M. Doratioto, Geralda Dias Aparecida, Olga Cabrera Garcia e Dinair Andrade da Silva. Os Estados Unidos foram estudados em termos das relações políticas e econômicas com o Brasil e mediante a visão dos diplomatas, como em Brasil e Estados Unidos nas representações de Oliveira Lima e Salvador de Mendonça (18701914): idéia sobre a inserção brasileira na América, de Américo de Lyra Júnior. Os países sul-americanos receberam atenção quanto aos aspectos políticos, econômicos e sociais, a exemplo de Colonização da Patagônia e sua dimensão internacional, de Ana Carolina Pompeu, e comparativamente - Acordos de livre comércio, desnacionalização e sistemas financeiros. Os casos de Brasil, México e Chile, de Igor Torres. A América Central mereceu um estudo sobre o papel do Brasil junto ao conflito regional desatado pela Revolução Nicaragüense, enquanto o Caribe foi abordado por meio da imigração da população haitiana e dos exilados cubanos. Na linha cultural, foi estudado o imaginário produzido pelos estúdios Disney durante a Segunda Guerra, da mulher nos HQs norte-americanos e dos Estados Unidos nos livros didáticos nacionais, ao lado da análise das comemorações do centenário da independência na América Hispânica e do problema da identidade jamaicana. Os indígenas por sua vez, foram analisados tanto nos tempos recentes mediante suas formas de organização no Brasil e no México, assim como no passado colonial, mediante o estudo da figura feminina em Por uma história possível: o feminino e o sagrado nos discursos dos cronistas e na historiografia sobre o império inca, de Susane de Oliveira.

Na UFF, constatamos a diversificação dos temas com questões mais específicas e a abertura em direção a uma ampla gama de abordagens: a política continua sendo dominante, mas articulada a outros domínios tais como o social, o cultural, o econômico 
e as relações internacionais. A comparação foi mobilizada em estudos a respeito da história intelectual como na tese Civilização e barbárie: a representação da nação nos textos de Sarmiento e do Visconde do Uruguai, de Maria Elisa N. de Sá Mader, assim como em outros relativos às universidades populares no Brasil e na Argentina, sobre a repressão no Cone Sul, a organização política dos desempregados argentinos e a experiência política dos conselhos comunitários na Venezuela chavista. A cultura chamou a atenção de diversos trabalhos, a exemplo de Um olhar sobre o país vizinho: representações do Brasil e da Argentina no contexto das relações diplomáticas (19301964), de Raque Paz dos Santos, assim como de outros a respeito da história do tango, a identidade nacional paraguaia e a filmografia de Hollywood. Os Estados Unidos também foram o objeto de várias outras pesquisas voltadas à compreensão dos movimentos de contestação dos anos 1960, das políticas de cooperação com a América Latina, da corrida armamentista e do ressurgimento das correntes de extrema-direita. As questões econômicas foram discutidas em estudos sobre o povoamento e produção na Província de Buenos Aires, o debate econômico em Cuba, ao lado da questão agrária no peronismo e no varguismo. Por sua vez, o período colonial foi visitado pelos estudos da religião, da pintura e das representações políticas dos cronistas, enquanto a moderna historiografia foi examinada em seus primórdios no Brasil e Argentina.

As teses e dissertações da UFRJ têm versado principalmente sobre a história política contemporânea, ao passo que uma menor parcela tratou do mundo colonial. Os seus orientadores foram Francisca de Azevedo, Jacqueline Hermann, Juliana Beatriz de A. Souza e Francisco Carlos Teixeira da Silva. A perspectiva política figura em estudos a respeito do Rio Grande do Sul e os caudilhos do Prata, das convenções sanitárias entre o Brasil império e as repúblicas do Prata e da repercussão diplomática das fugas de escravos para a Bolívia. Os Estados Unidos foram abordados em pesquisa que tratam do sindicalismo no New Deal e da extrema-direita atual. O peronismo foi examinado no âmbito da política das províncias e a questão nacional tratada tomando-se três países, México, Brasil e Argentina. No campo da cultura, a identidade nacional mexicana foi analisada através do discurso antropológico e artístico, e o Brasil e Argentina foram uma vez mais comparados quanto aos projetos de nação por meio das revistas ilustradas do Rio de Janeiro e de Buenos Aires. Quanto ao período colonial, as mulheres indígenas do Peru subsidiaram três pesquisas que abordaram relações de gênero, formas de união 
conjugal e sua participação social, ao lado de outras voltadas para as instituições religiosas e educativas, a exemplo do Real Colégio de San Carlos de Lima.

Nas universidades do Rio Grande do Sul, a região platina continua tendo uma posição privilegiada nas pesquisas, porém observa-se a ampliação desse recorte por meio da inclusão de estudos sobre outros países do continente. A história política permanece majoritária, seguida pelas relações internacionais e a história econômica, observando-se o incremento das temáticas culturais.

Os trabalhos da PUC-RS têm se concentrado em história política, relações internacionais, economia e história social, tanto do período colonial quanto dos séculos XIX e XX. Em relação à história colonial os principais objetos estudados foram a organização das fronteiras e do espaço urbano colonial, as missões jesuíticas tanto na dimensão política quanto cultural, a história indígena em suas nova abordagens, relações dos vice-reinados Prata e Peru com a América Portuguesa, as reformas bourbônicas e as guerras de independência. Os temas políticos mostraram-se dominantes nas pesquisas do período independente, tendo o Uruguai, a Argentina e o Paraguai como focos principais. O Uruguai foi estudado tanto em relação ao processo de transformações no século XIX quanto na resistência política ao autoritarismo político no XX. Os golpes de estado e os regimes de exceção na Argentina foram investigados em trabalhos relativos à ditadura na argentina, à questão dos direitos humanos e à deposição do presidente Arturo Frondizi, investigada mediante sua repercussão na imprensa carioca. Por sua vez, os países acima também foram examinados na perspectiva das relações internacionais, em monografias sobre a Província Cisplatina, a Guerra do Pacifico, O Pacto ABC, as relações Brasil-Argentina, as conexões entre o Uruguai - Rio Grande do Sul e a formação de uma identidade regional platina. No campo da economia foram trabalhados os projetos da CEPAL, as transformações econômicas regionais e as ações de integração.

Conformando cerca de metade dos trabalhos da UNISINOS, a política tem balizado a investigação de fenômenos no espaço platino tais como as relações entre o Brasil e o Uruguai em vários momentos do século XIX. Também foram analisados temas sobre a Internacional Comunista na América Latina, a trajetória da esquerda uruguaia e as relações Brasil - Estados Unidos. O período colonial continua tendo considerável espaço em relação aos anos anteriores, na exploração de novas questões 
em pesquisas sobre indígenas, missionários e instituições. Cabe mencionar ainda estudos em perspectiva cultural, a respeito da imagem da mulher na guerra do Paraguai, do cinema no peronismo e do imaginário de maias e astecas. A orientação dos trabalhos tem estado sob a responsabilidade de Heloísa Reichel, Werner Altmann, Eliane Fleck, Pedro Ignácio Schmitz e Flávio Heinz.

A UFRGS tem mantido como principais orientadores César Augusto Barcellos Guazzelli, Susana Bleil de Souza e Cláudia Wassermann. Os trabalhos versam principalmente sobre o período independente, concentrando-se em política e relações internacionais. Foram estudados os caudilhos e montoneras da província argentina de La Rioja, o sentido político da Revolução Mexicana; o autoritarismo no Uruguai e a repressão no Cone Sul, as relações do Partido Aprista Peruano com Haya de la Torre, ao lado de fenômenos mais recentes o neozapatismo mexicano, o movimento piquetero e o neofascismo na Argentina. Como nos dois cursos anteriores, as questões internacionais sobressaem nos estudos a respeito das relações entre o Brasil e o Uruguai no século XIX, da construção da identidade regional no Rio Grande do Sul, da diplomacia brasileira para a região e a formação do Mercosul. No campo da economia, merecem destaque as pesquisas sobre o processo econômico da Argentina agro-exportadora, da formação do capitalismo em Córdoba e as organizações empresariais na Argentina e Brasil. Por sua vez, os estudos coloniais deram atenção às relações entre índios e missionários religiosos e às relações comerciais e sociais na Colônia do Sacramento

Finalmente, entre os demais cursos merece destaque a produção da UFMG, com pesquisas em torno da imprensa, intelectuais, viagens e memória, sob a coordenação da Prof ${ }^{a}$ Kátia Gerab Baggio, cujos resultados materializaram-se em teses como Intelectuais, política e literatura na América Latina: o debate sobre revolução e socialismo em Cortázar, García Márquez e Vargas Llosa (1958-2005), de Adriane Vidal Costa, e Octavio Paz: estratégias de reconhecimento, polêmicas políticas e debates midiáticos no México, de Priscilla Dorella. E em dissertações de mestrado, a exemplo de Americanismo(s) no Uruguai: os olhares entrecruzados dos intelectuais sobre a América Latina e os Estados Unidos (1917-1969), Mateus Fávaro Reis, e $O$ México como "lição": a Revolução Mexicana nos grandes jornais brasileiros $e$ argentinos (1910-1915), de Natally Vieira Dias. 


\section{Conclusão}

Os cursos até agora mencionados são em geral os mais antigos e constituíram a base da consolidação da pesquisa de História da América nas universidades brasileiras. No entanto, a área vem se expandindo nos últimos anos graças às iniciativas de outros programas que não temos condições de tratar de forma adequada no curto espaço deste artigo. ${ }^{7}$ Também deixamos de lado aspectos que mereceriam atenção cuidadosa, a exemplo das pesquisas e publicações dos docentes, e das atividades coletivas, tais como o Projeto Temático Cultura e Política nas Américas: circulação de idéias e configuração de identidades (séculos XIX e XX), desenvolvido pela USP, UNESP e UNIFESP $^{8}$, e o projeto Linguagem da modernidade na América Ibérica, da PUC-RJ. ${ }^{9}$

Longe de constituir uma reflexão sistemática a respeito da produção de América, estas notas visam fornecer elementos para uma aproximação a um tema merecedor de outras reflexões. A perspectiva do conjunto das universidades nos leva a considerar que o desenvolvimento da pesquisa de América é o fruto da articulação de iniciativas levadas adiante em diversos lugares do país. A pluralidade das mesmas se reflete nas particularidades de cada um dos cursos e no perfil dos trabalhos realizados, os quais respondem tanto à história de cada uma das instituições quanto aos problemas colocados pelos pesquisadores nas diferentes regiões de um país continental como o Brasil.

A realização de pesquisas de História da América remonta a varias décadas, manifestando-se nos primeiros anos de funcionamento da Faculdade de Filosofia da USP. Nas décadas de 1960/1970, tais estudos foram retomados na mesma universidade e iniciados na UFF, para, no entanto, definharem nos anos oitenta. A descontinuidade da

\footnotetext{
7 PUC-RJ, UERJ, UFG, USS, UFSC, UFJF, UFOP, UFES, UEM, UFPR, UNIOESTE, UEL, UFPE, UFBA e UFMS.

${ }^{8}$ Financiado pela FAPESP, entre 2007 e 2010, sob a supervisão geral da Prof ${ }^{a}$ Maria Ligia Prado, o projeto foi composto pelos professores Maria Helena Capelato, Gabriela Pellegrino Soares, Mary Anne Junqueira, Tânia da Costa Garcia, Stella Maris Scatena Franco Vilardaga, Carlos Alberto Sampaio Barbosa e José Luis Bendicho Beired, além de pós-doutorandos, doutorandos, mestrandos e alunos de iniciação científica. As pesquisas estiveram organizadas em torno de três grandes núcleos temáticos: a) Identidades culturais e projetos políticos no mundo americano e ibérico; b) Culturas imperiais e circulação de idéias nas Américas (século XIX); c) Artistas, intelectuais e identidades na América Latina Contemporânea. Os seminários, orientações e publicações podem consultadas em: <http://www.fflch.usp.br/dh/leha/>.

${ }^{9}$ Coordenado pelos Profs. Marco Antonio Pamplona e Maria Elisa N. de Sá Mäder.
} 
pesquisa docente, do trabalho de orientação e de formação de pesquisadores foram elementos limitadores para a organização desse campo de pesquisa em uma época em que mesmo a área de Brasil ainda estava concentrada em poucos núcleos universitários. A organização da área dependeu fortemente do empenho de pesquisadores dispostos a investir seus esforços em um trabalho de longo prazo para a produção de conhecimentos em dia com a historiografia internacional e a formação de outros historiadores em condições de disseminar essa prática cientifica nas diversas instituições do país. Portanto, a sua consolidação é relativamente recente uma vez que apenas no século XXI configurou-se uma situação em que os doutorados de América passaram a tornar-se uma rotina em um conjunto de programas de pós-graduação, de modo a garantir a reposição dos profissionais, o aprimoramento da pesquisa, a internacionalização dos resultados e a ampliação do próprio campo de investigação.

Outra ordem de questões diz respeito à evolução dos objetos e das abordagens. Entendemos que as opções foram balizadas por um conjunto de referências que incluiu tanto a historiografia dos países americanos estudados quanto os debates da produção histórica brasileira e internacional. Ou seja, é possível que a escrita da História da América no Brasil esteja marcada por certas peculiaridades decorrentes justamente do lugar aonde ela foi realizada. Uma vantagem é a possibilidade de ver os fenômenos sob outros ângulos, propor novas questões e explicações, como no caso da comparação, método fecundo que vem propiciando interessantes pesquisas em nos diversos cursos.

A descrição da produção evidencia que a história política e a história cultural têm informado a maior parte dos trabalhos dos últimos anos por meio de um variado espectro de temas, fontes e problemas. Majoritária até a década de 1970, a história econômica perdeu lugar nas décadas seguintes em função das críticas às concepções deterministas, o que não impediu a sua atualização cientifica e a continuidade das pesquisas em diversas instituições. De forma similar, a história colonial passou por uma renovação temática e teórica que tem buscado analisar, por exemplo, os fenômenos de transculturação e resistência, as questões de gênero e a produção de imaginários sociais. As relações internacionais constituem outro campo crescentemente explorado, que tem permitido o estudo do Brasil frente não só aos seus vizinhos, mas também em relação aos países mais distantes, a exemplo dos Estados Unidos, no exame tanto de problemas clássicos quanto de novos objetos. Em suma, a qualidade e criatividade da produção 
elaborada no Brasil não apenas tem colaborado para o aperfeiçoamento do campo historiográfico brasileiro, com positiva repercussão no ensino e no debate público, mas a colocaram em um patamar que a tem levado a transcender as fronteiras do país, convertendo-a em uma referência que tem dialogado e contribuído com a historiografia internacional.

Para encerrar estas reflexões, cabe perguntar se continua válida a afirmação com a qual iniciamos o artigo. Por inúmeros fatores, certamente o Brasil já não se encontra de costas para a América Latina. E nem em relação aos Estados Unidos. Ao contrário, provavelmente é o país latino-americano que tem despendido maior empenho acadêmico no sentido de conhecer as Américas e estabelecer laços acadêmicos sem abrir mão do espírito crítico que deve pautar o trabalho científico e intelectual.

\section{Referências bibliográficas}

BEIRED, José Luis Bendicho. A pesquisa de História da América: sua trajetória nas universidades paulistas (1942-2004). In: Revista de História. São Paulo, USP, nº 153, p. $35-52,2^{\circ}$ sem 2005.

BEIRED, José Luis Bendicho. Catálogo de teses e dissertações de História da América produzidas nas universidades paulistas (1942-2004). Assis: FCL/Assis-Unesp Publicações, Disponível em: <http://www.cedap.assis.unesp.br/publicacoes/america/america.html > Acesso: 15 jun 2012.

CAPELATO, Maria Helena Rolim (coord.). Produção Histórica no Brasil. 1985 1994. V. 1. São Paulo: Xamã, 1995.

DIÁLOGOS. Maringá, UEM, v.8, no. 2, jul/dez 2004.

FRAGOSO, João Fragoso \& FLORENTINO, Manolo. História Econômica. In: CARDOSO, Ciro F. \& VAINFAS, Ronaldo (orgs.). Domínios da História. Rio de Janeiro: Campus, 1997.

GOUVÊA, Fátima et alii. Uma história em três tempos: experiências de pesquisa e ensino de História das Américas. In: Diálogos, v.8, no. 2, p. 105-132, jul/dez 2004.

SILVA, Vitória Rodrigues e. O ensino de História da América no Brasil. Diálogos, v.8, no. 2 , p. $83-104$, jul/dez 2004. 
SOARES, Gabriela Pellegrino; PINTO, Júlio Pimentel. A América Latina no universo das edições brasileiras. In: Diálogos, v.8, no. 2, p. 133 - 152, jul/dez 2004. 